\title{
Chemical Reduction of $\mathrm{Nd}_{1.85} \mathrm{Ce}_{0.15} \mathrm{CuO}_{4-\delta}$ Powders in Supercritical Sodium Ammonia Solutions
}

\author{
Yasmin Dias, ${ }^{1}$ Hui Wang, ${ }^{2}$ Haiqing Zhou, ${ }^{2}$ Feng Lin, ${ }^{3}$ and Yucheng Lan ${ }^{1,2}$ \\ ${ }^{1}$ Department of Physics and Engineering Physics, Morgan State University, Baltimore, MD 21251, USA \\ ${ }^{2}$ Department of Physics, University of Houston, Houston, TX 77204, USA \\ ${ }^{3}$ State Key Laboratory for Mesoscopic Physics, School of Physics, Peking University, Beijing 100871, China
}

Correspondence should be addressed to Feng Lin; linf@pku.edu.cn and Yucheng Lan; yucheng.lan@morgan.edu

Received 14 December 2014; Revised 5 March 2015; Accepted 12 March 2015

Academic Editor: Markus R. Wagner

Copyright (C) 2015 Yasmin Dias et al. This is an open access article distributed under the Creative Commons Attribution License, which permits unrestricted use, distribution, and reproduction in any medium, provided the original work is properly cited.

\begin{abstract}
$\mathrm{Nd}_{1.85} \mathrm{Ce}_{0.15} \mathrm{CuO}_{4-\delta}$ powders are chemically reduced in supercritical sodium ammonia solutions from room temperature to $350^{\circ} \mathrm{C}$. The crystallographic structure of the reduced powders is investigated from Rietveld refinement of X-ray powder diffraction. The atomic positions are maintained constant within experimental errors while temperature factors of all atoms increase significantly after the chemical treatments, especially of $\mathrm{Nd} / \mathrm{Ce}$ atoms. The ammonothermally reduced $\mathrm{Nd}_{1.85} \mathrm{Ce}_{0.15} \mathrm{CuO}_{4-\delta}$ powders show diamagnetic below $24 \mathrm{~K}$ which is contributed to the lower oxygen content and higher temperature factors of atoms in the treated compound. The ammonothermal method paves a new way to reduce oxides in supercritical solutions near room temperature.
\end{abstract}

\section{Introduction}

The electron-doped $(\mathrm{Nd}, \mathrm{Ce})_{2} \mathrm{CuO}_{4-\delta} \mathrm{T}^{\prime}$-phase is the best candidate to investigate superconductivity mechanisms [14] because of its simple crystallographic structure as well as the hole-doped $\mathrm{La}_{2} \mathrm{CuO}_{4+y}$ T-phase. The $\mathrm{T}^{\prime}$-phase superconductor has been synthesized through rare-earth substitution on the $\mathrm{Nd}$ site by $\mathrm{Ce}[5,6]$, through fluorine substitution for oxygen [6,7], or through reduction process $[1,8-10]$ at high temperatures of $800-1100^{\circ} \mathrm{C}$. These traditional high temperature procedures have successfully reduced copper on $\mathrm{CuO}_{2}$ sheets, inducing superconductivity of the $\mathrm{T}^{\prime}$-phase with transition temperature $T_{c}=22-27 \mathrm{~K}[1,5-10]$. However it is still challenging to adjust the chemical state of the $\mathrm{CuO}_{2}$ sheets through low temperature treatments. Up to date there is no report on chemical reductions of the $\mathrm{T}^{\prime}$-phase at low temperatures to induce superconductivity.

On the contrary, the hole-doped $\mathrm{La}_{2} \mathrm{CuO}_{4+y}$ T-phase, the counterpart of the electron-doped $\mathrm{T}^{\prime}$-phase, can be chemically oxidized by both traditional high temperature treatments [11, 12] and low temperature treatments [1315] to achieve superconductivity. It is well known that the superconducting T-phase can be prepared through alkaline earth substitution [11] and high-oxygen pressure treatment [12] at high temperature over $800^{\circ} \mathrm{C} . \mathrm{La}_{2} \mathrm{CuO}_{4}$ has also been oxidized in aqueous solutions below $150^{\circ} \mathrm{C}$ to achieve superconductivity when strong oxidizing agents (such as potassium permanganate $[13,14]$ and sodium hypochlorite [15]) are dissolved in water as solvents. Superconductivity transition temperatures $T_{c}$ of the low-temperature oxidized T-phase are $\sim 40 \mathrm{~K}$ [13-15], higher than that of the T-phase $\left(T_{c} \sim 30 \mathrm{~K}[11,12]\right)$ prepared by high temperature treatments, indicating the effectiveness of low-temperature aqueous chemical treatments.

The reduction of the electron-doped $(\mathrm{Nd}, \mathrm{Ce})_{2} \mathrm{CuO}_{4-\delta} \mathrm{T}^{\prime}$ phase is the counterpart of the oxidization of the hole-doped $\mathrm{La}_{2} \mathrm{CuO}_{4+y}$ T-phase. It has been reported that supercritical hydrothermal technique is a unique method to successfully dope oxygen into the hole-doped $\mathrm{La}_{2} \mathrm{CuO}_{4+y}$ T-phase in aqueous solutions at $100-180^{\circ} \mathrm{C}$. The achieved transition temperature $T_{c}(42 \mathrm{~K}[14,16])$ of the T-phase superconductors is slightly higher than that achieved by traditional lowtemperature chemical treatments $\left(T_{c} \sim 40 \mathrm{~K}[13]\right)$, showing the best capability to oxidize superconductors among various 
low-temperature aqueous oxidization treatments. Then two questions raise: (1) is there a supercritical reduction method (counterpart of supercritical hydrothermal technique) to reduce oxides? (2) Is it possible to reduce the electron-doped $\mathrm{T}^{\prime}$-phase (counterpart of the T-phase) at low temperatures?

In this research, $\mathrm{Nd}_{1.85} \mathrm{Ce}_{0.15} \mathrm{CuO}_{4-\delta} \mathrm{T}^{\prime}$-phase powders are chemically reduced in a supercritical sodium metal ammonia solution, counterpart of the oxidation hydrothermal solutions, below $350^{\circ} \mathrm{C}$. The low-temperature reduction treatments greatly affect crystallographic structures and magnetic properties of the powders.

\section{Materials and Methods}

The polycrystalline $\mathrm{Nd}_{1.85} \mathrm{Ce}_{0.15} \mathrm{CuO}_{4-\delta}$ samples used for the experiments are prepared from oxides by a solid state reaction. Appropriate quantities of $\mathrm{Nd}_{2} \mathrm{O}_{3}, \mathrm{CeO}_{2}$, and $\mathrm{CuO}$ powders are mechanically mixed, ground in an agate mortar, sintered in air at $950-1100 \pm 5^{\circ} \mathrm{C}$ for four days, with intermittent regrindings, removed from furnaces, and quenched in air to room temperature. X-ray powder diffraction patterns indicate that the samples are single phase. The single phase samples are then ground into powders and further annealed in a floating $\mathrm{Ar}$ atmosphere at $930 \pm 5^{\circ} \mathrm{C}$ for $24 \mathrm{~h}$ as starting samples.

An autoclave is pre-cooled by liquid nitrogen. Then liquid ammonia is poured from a high pressure (130 PSI) tank into the autoclave. An alkali metal bar is cut to a desired weight under a protected atmosphere and dropped into the liquid ammonia contained in a clean quartz cuvette to form an alkali metal ammonia solution. $\mathrm{Nd}_{1.85} \mathrm{Ce}_{0.15} \mathrm{CuO}_{4-\delta}$ starting powders are then dropped into the ammonia solution once the alkali solution turns blue completely. The autoclave is cooled down to $-33^{\circ} \mathrm{C}$, the boiling point of ammonia at one atmosphere. The autoclave is then sealed quickly at one atmosphere before the autoclave is warmed up. The sealed autoclave is heated up to $10-350^{\circ} \mathrm{C}$ for $72 \mathrm{~h}$ in a furnace. According to ammonia phase diagram, the ammonia pressure in the autoclave is $20-1000 \mathrm{kPa}$ depending on the treatment temperature and the liquid ammonia filling rate. Then the ammonothermally treated powders are collected, filtered, thoroughly washed with distilled water and ethanol in sequence, and dried at room temperature in vacuum. The details of the ammonothermal procedure have been described in other literatures [17-19].

The X-ray powder diffraction (XRD) patterns are measured on a Rigaku D/max-2400 diffractometer with $\mathrm{Cu}-\mathrm{K}_{\alpha}$ radiation at room temperature. All data are collected in a step scanning mode with a step of $0.02^{\circ}(2 \theta)$ and a measuring time of $0.5 \mathrm{~s}$ per step. An angular range from $10^{\circ}$ to $80^{\circ}$ is applied and NBS SRM $640 \mathrm{Si}$ is added as an internal standard for lattice parameter determinations. The lattice parameters are calculated using the DICVOL91 program [20] after the experimental peak positions are calibrated. The $\mathrm{X}$ ray diffraction data are also collected over an angular range of $10-130^{\circ}$ for Rietveld refinements. The divergence, scattering, and receiving slits are set at $1^{\circ}, 1^{\circ}$, and $0.10 \mathrm{~mm}$, respectively. A total of 6001 points with a maximum count of about 15,000 and 123 independent reflections are measured for Rietveld refinements. The Rietveld refinement is then carried out using the computer program DBWS-9411 [21].

Magnetic susceptibility of the powders is measured with a SQUID magnetometer under a DC magnetic field down to $4.2 \mathrm{~K}$.

The oxygen content of the samples is chemically determined by an iodometric titration [22]. Sodium thiosulfate titrant is standardized against $99.999 \%$-pure $\mathrm{CuO}$ powders. The $\mathrm{Nd}_{1.85} \mathrm{Ce}_{0.15} \mathrm{CuO}_{4-\delta}$ powders are put into $50 \%$ potassium iodide solutions at room temperature and dissolved with $10 \%$ hydrochloric acid. Starch with a concentration of $2 \%$ is used as an endpoint indicator.

\section{Results and Discussion}

The powders are black before and after the ammonothermal treatments when the treatment temperature is lower than $150^{\circ} \mathrm{C}$. Scanning electron microscopic observation shows that the grain size of the powders is slightly decreased by $5 \%$ to $10 \%$ after the treatments. XRD studies indicate that the $\mathrm{T}^{\prime}$ phase is thermally stable up to $150^{\circ} \mathrm{C}$ in the sodium ammonia solution. All the powders are single phase with a space group of $\mathrm{I} 4 / \mathrm{mmm}$ ( $\mathrm{T}^{\prime}$-phase) before and after the reduction treatments. Figure 1 shows XRD patterns of the $\mathrm{T}^{\prime}$-phase powders before and after the ammonothermal treatments at $54^{\circ} \mathrm{C}$. Lattice parameters are nearly identical within experimental errors. $a=b=3.9430(4) \AA$ and $c=12.070(2) \AA$ before the powders are ammonothermally treated while $a=b=$ 3.9433(3) $\AA$ and $c=12.072(1) \AA$ after the powders are ammonothermally treated at $54^{\circ} \mathrm{C}$.

The ammonothermal reduction treatments affect magnetization properties of the $\mathrm{T}^{\prime}$-phase. SQUID magnetic measurements indicate that the untreated $\mathrm{T}^{\prime}$ phase $\mathrm{Nd}_{1.85} \mathrm{Ce}_{0.15} \mathrm{CuO}_{4-\delta}$ powders did not show any magnetization transition above $4.2 \mathrm{~K}$ to $50 \mathrm{~K}$, similar to the reported earlier [23]. After the powder is ammonothermally treated at $54^{\circ} \mathrm{C}$, a magnetic transition is observed near $24 \mathrm{~K}$. Figure 2 is the susceptibility $\chi$ versus temperature $T$ in a temperature range of $4.2-50 \mathrm{~K}$ for the $\mathrm{Nd}_{1.85} \mathrm{Ce}_{0.15} \mathrm{CuO}_{4-\delta}$ powders that are ammonothermally treated at $54^{\circ} \mathrm{C}$. The powders are paramagnetic above $24 \mathrm{~K}$ while they are diamagnetic below $22 \mathrm{~K}$. The transition temperature of $24 \mathrm{~K}$ is comparable to that $\left(T_{c}=22-24 \mathrm{~K}\right)$ achieved by the traditional high temperature reduction treatments at 850$1050^{\circ} \mathrm{C}[1,3,8-10]$, slightly lower than that $\left(T_{c}=27 \mathrm{~K}\right)$ achieved by the fluorine substitution for oxygen [7]. Therefore the supercritical ammonothermal reduction treatments are a simple but effective method to achieve superconductivity in the $\mathrm{T}^{\prime}$-phase.

The oxygen content $(4-\delta)$ of the $\mathrm{T}^{\prime}$-phase powders is determined by the iodometric titration. The oxygen content of the as-prepared powders is 3.975(5) while it is 3.961(5) of the chemically treated powders at $54^{\circ} \mathrm{C}$. Therefore the supercritical ammonothermal treatments lower the oxygen content of the $\mathrm{T}^{\prime}$-phase and reduce the chemical state of the $\mathrm{CuO}_{2}$ sheets, resulting in the diamagnetic properties of the $\mathrm{T}^{\prime}$-phase powders. 


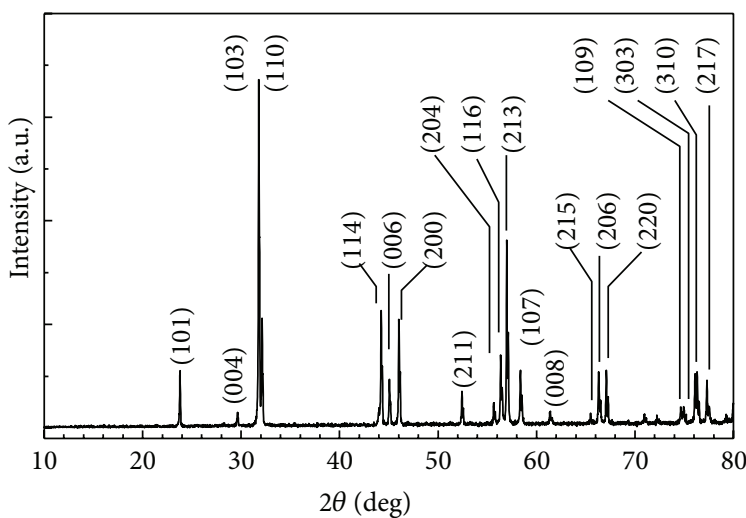

(a)

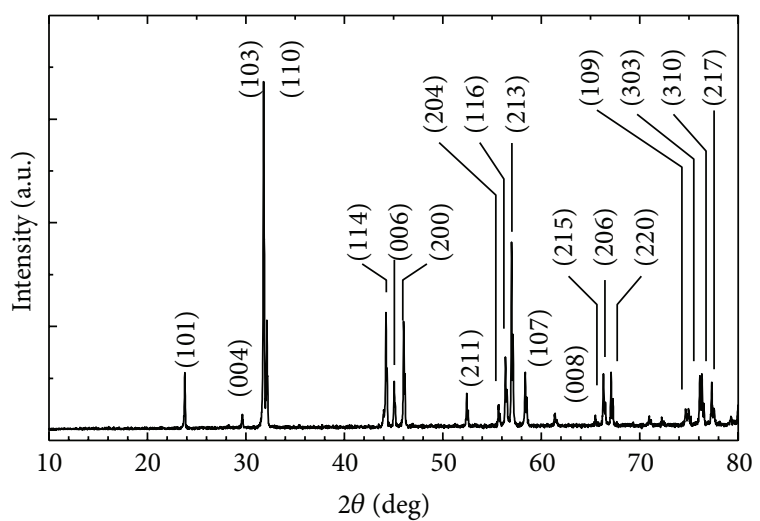

(b)

Figure 1: X-ray diffraction patterns of $\mathrm{Nd}_{1.85} \mathrm{Ce}_{0.15} \mathrm{CuO}_{4-\delta}$ powders (a) before and (b) after ammonothermal treatments at $54^{\circ} \mathrm{C}$ in sodium ammonia solutions.

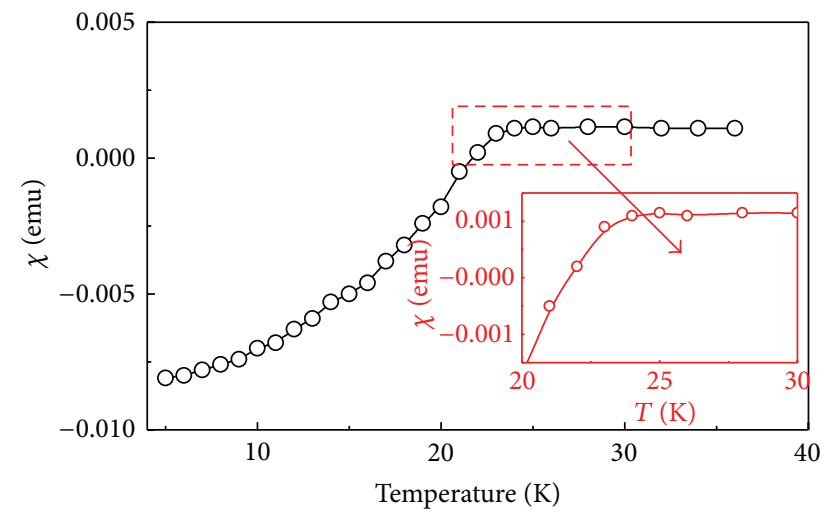

Figure 2: Magnetic susceptibility $\chi$ of treated $\mathrm{Nd}_{1.85} \mathrm{Ce}_{0.15} \mathrm{CuO}_{3.961}$ as a function of temperature $T$. The zero-field-cooled measurement is carried out under 10 Oe. The insert shows enlarged susceptibility as a function of temperature near the transition. The powders are ammonothermally reduced at $54^{\circ} \mathrm{C}$ in sodium ammonia solutions.

It is well known that alkali metal, such as sodium, is very soluble in liquid ammonia [24]. Sodium produces solvated cations and solvated electrons in liquid ammonia:

$$
\mathrm{Na}+(x+y) \mathrm{NH}_{3} \longrightarrow\left[\mathrm{Na}\left(\mathrm{NH}_{3}\right)_{y}\right]^{+}+\mathrm{e}^{-}\left(\mathrm{NH}_{3}\right)_{x}
$$

where $\mathrm{e}^{-}$is the solvated electron in the ammonia solution. The $\left[\mathrm{e}^{-}\left(\mathrm{NH}_{3}\right)_{x}\right]$ ions can reduce oxides effectively. Thus the alkali ammonia solution is one of the strongest reductive solutions [24], providing a homogeneous environment to reduce $(\mathrm{Nd}, \mathrm{Ce})_{2} \mathrm{CuO}_{4-\delta} \mathrm{T}^{\prime}$-phase compounds here under supercritical conditions. The abundant solvated electrons in the ammonia solution can directly dope into the $\mathrm{CuO}_{2}$ sheets of the $\mathrm{T}^{\prime}$-phase, changing the carrier concentration of $\mathrm{CuO}_{2}$ sheets to induce diamagnetic properties of the $\mathrm{T}^{\prime}$-phase below $24 \mathrm{~K}$.

However, the sodium ammonia solution is not thermally stable at high temperatures, $2 \mathrm{Na}+2 \mathrm{NH}_{3} \rightarrow 2 \mathrm{NaNH}_{2}+\mathrm{H}_{2} \uparrow$, and loses reduction activity over $100^{\circ} \mathrm{C}$. In order to examine temperature effects, the $(\mathrm{Nd}, \mathrm{Ce})_{2} \mathrm{CuO}_{4-\delta} \mathrm{T}^{\prime}$-phase powders are also chemically treated in the sodium ammonia solution over $100^{\circ} \mathrm{C}$. No diamagnetic behavior of the treated powders is detected. The reduction activity of the sodium solution is also lower at lower temperatures (room temperature to $30^{\circ} \mathrm{C}$ ), resulting in no significant magnetic change of the $\mathrm{T}^{\prime}$-phase powders. The optimum treatment temperature is $54^{\circ} \mathrm{C}$.

Besides sodium ammonia solution, other alkali metal (such as potassium and lithium) ammonia solutions have similar chemical activities and should also work as reduction solutions to induce diamagnetic characterization of $\mathrm{T}^{\prime}$-phase powders. We test potassium ammonia solutions and $(\mathrm{Nd}, \mathrm{Ce})_{2} \mathrm{CuO}_{4-\delta} \mathrm{T}^{\prime}$-phase powders can be reduced in potassium ammonia solutions at $50^{\circ} \mathrm{C}$.

In order to explore how the ammonothermal treatments affect the crystallographic structures of $\mathrm{Nd}_{1.85} \mathrm{Ce}_{0.15} \mathrm{CuO}_{4-\delta}$ powders besides the lattice parameters and oxygen content, X-ray Rietveld structural refinements of the powders are carried out to determine more detailed crystallographic structures of the powders.

The Rietveld refinements are performed with initial positional parameters according to those of $\mathrm{Nd}_{2} \mathrm{CuO}_{4}$ [25]. $\mathrm{Nd}$ and Ce atoms are located statistically on the site $4 \mathrm{e}(0,0, z)$ with the initial atomic ratio $\mathrm{Nd}: \mathrm{Ce}=1.85: 0.15$. The oxygen atoms are set on the sites $4 \mathrm{c}(0,0.5,0)$ and $4 \mathrm{~d}(0,0.5$, $0.25)$. The total oxygen content $4-\delta$ is 3.961 for the reduced samples (Figure 3(b)) and 3.975 for the untreated samples (Figure 3(a)), according to the iodometric titration. The $\mathrm{Cu}$ atoms are put on the site $2 \mathrm{a}(0,0,0)$. The space group of the powders is $\mathrm{I} 4 / \mathrm{mmm}$. X-ray diffraction peaks are fitted as a pseudo-Voigt function in shape. Background values are obtained by linear interpolation between average values in regions between diffraction peaks. The Debye-Waller factor for the compounds is corrected for absorption.

Figure 3 shows the final Rietveld refinement patterns of the untreated and treated powders. Table 1 lists the final Rietveld refined positional and thermal parameters of atoms in the samples. 
TABLE 1: Final Rietveld refined parameters of $\mathrm{Nd}_{1.85} \mathrm{Ce}_{0.15} \mathrm{CuO}_{4-\delta}$ powders from X-ray powder diffraction data.

\begin{tabular}{lccccc}
\hline Atom & Site & $x / a$ & $y / b$ & $z / c$ & $B\left(\AA^{2}\right)$ \\
\hline $\mathrm{Cu}$ & $2 \mathrm{a}$ & 0 & 0 & $0^{\dagger}, 0^{\S}$ & $0.44(7)^{\dagger}, 0.19(6)^{\S}$ \\
$\mathrm{Nd}$ & $4 \mathrm{e}$ & 0 & 0 & $0.3523(5)^{\dagger}, 0.3524(5)^{\S}$ & $0.44(6)^{\dagger}, 0.04(2)^{\S}$ \\
$\mathrm{Ce}$ & $4 \mathrm{e}$ & 0 & $1 / 2$ & $0.3523(5)^{\dagger}, 0.3524(5)^{\S}$ & $0.44(6)^{\dagger}, 0.04(2)^{\S}$ \\
$\mathrm{O}(1)$ & $4 \mathrm{c}$ & 0 & $0^{\dagger} / 0^{\S}$ & $0.90(1)^{\dagger}, 0.20(1)^{\S}$ \\
$\mathrm{O}(2)$ & $4 \mathrm{~d}$ & 0 & $1 / 2$ & $1 / 4^{\dagger}, 1 / 4^{\S}$ & $0.80(1)^{\dagger}, 0.70(1)^{\S}$ \\
\hline
\end{tabular}

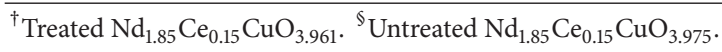

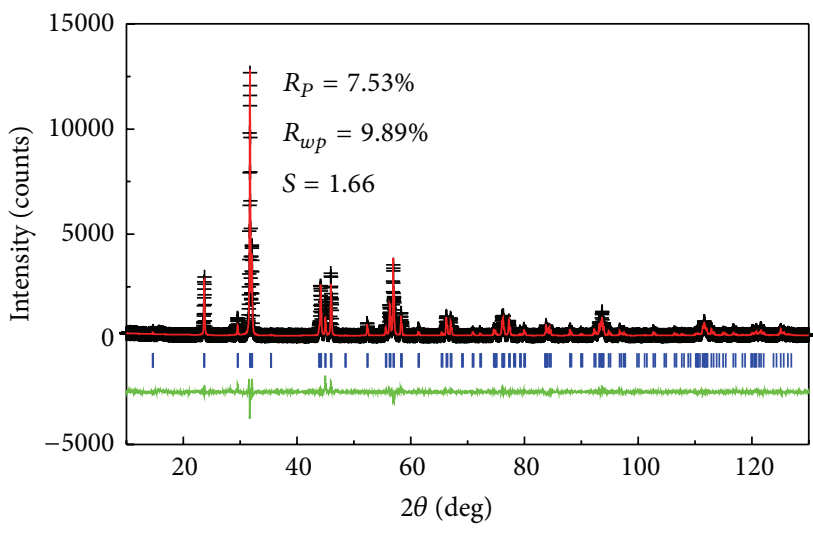

+ Experimental values _ Difference

Calculated pattern I hkl

(a)

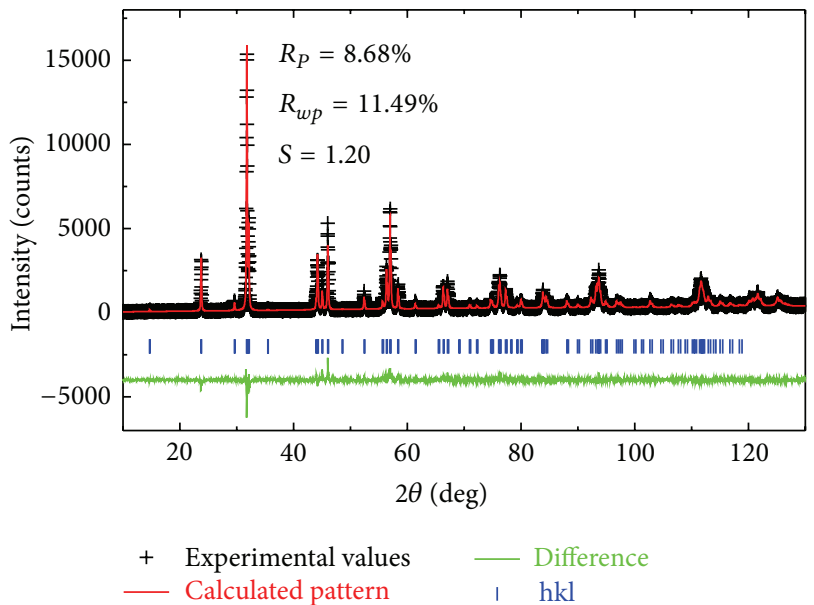

(b)

Figure 3: Final Rietveld refinement patterns of (a) $\mathrm{Nd}_{1.85} \mathrm{Ce}_{0.15} \mathrm{CuO}_{3.975}$ powders without treatments and (b) $\mathrm{Nd}_{1.85} \mathrm{Ce}_{0.15} \mathrm{CuO}_{3.961}$ powders ammonothermally treated at $54^{\circ} \mathrm{C}$ in sodium ammonia solutions. Black crosses represent the experimental values and the red solid line the calculated pattern. The green solid line at the bottom is the difference between the experimental and calculated data. The blue bars represent the position of Bragg reflections.

The ammonothermal treatments do not affect the atomic positions within experimental errors. The fact is in good agreement with previous neutron Rietveld refinements [26] of superconducting and nonsuperconducting $(\mathrm{Nd}, \mathrm{Ce}) \mathrm{CuO}_{4-y} \mathrm{~T}^{\prime}$-phases.

The thermal parameters of the $\mathrm{T}^{\prime}$-phase compounds are increased significantly by the ammonothermal treatments. The $B$ in Table 1 is the isotropic temperature factor, $B=$ $8 \pi^{2} \overline{u^{2}}$, where $u$ is the vibrational amplitude of atoms. The ammonothermal treatments have enhanced the isotropic temperature factor $B$ of $\mathrm{O}(1)$ atoms 4.5 times while they have not affected that of $\mathrm{O}(2)$ atoms within experimental errors. The result is in agreement with the Raman and infrared transmission studies [2] and the microscopic oxygen-reduction mechanism of $\mathrm{T}^{\prime}$-phase $[4,5]$. It is suggested that the reduction processes only remove oxygen in the $\mathrm{CuO}_{2}$ sheets to destroy the long-range antiferromagnetism and increase the mobility of charge carriers for superconductivity, while they do not affect apical oxygen, resulting in the great change of thermal vibration of $\mathrm{O}(1)$ atoms but not $\mathrm{O}(2)$ atoms.

Simultaneously, the thermal parameter $B$ of $\mathrm{Nd}$ atoms and $\mathrm{Ce}$ atoms is increased 11 times after the ammonothermal treatments while that of $\mathrm{Cu}$ is increased 2.3 times. The significant changes of the thermal parameters should also be important factors to cause the diamagnetic behavior shown in Figure 2.

\section{Conclusions}

The $\mathrm{T}^{\prime}$-phase $\mathrm{Nd}_{1.85} \mathrm{Ce}_{0.15} \mathrm{CuO}_{4-\delta}$ compounds were chemically reduced at $54^{\circ} \mathrm{C}$ in supercritical sodium ammonia solutions, resulting in a diamagnetic transition near $24 \mathrm{~K}$. Xray Rietveld refinements indicated that the ammonothermal treatments enhanced the isotropic temperature factors of atoms, especially $\mathrm{Nd} / \mathrm{Ce}$ atoms and $\mathrm{O}(1)$ atoms, of the oxide powders while their lattice parameters were unchanged. The strong reduction environment of sodium ammonia solutions induced the diamagnetic properties of the $\mathrm{T}^{\prime}$-phase.

\section{Conflict of Interests}

The authors declare that there is no conflict of interests regarding the publication of this paper.

\section{Acknowledgments}

The work is partially supported by the Defense Threat Reduction Agency under Grant HDTRA122221. Yucheng Lan 
acknowledges the support from US Department of Energy under the Contract DE-NA0000720 through the Program of S. P. Massie Chair of Excellence. Feng Lin is supported by the National Basic Research Program of China (973 Program), Grant no. 2012CB933004.

\section{References}

[1] A. J. Schultz, J. D. Jorgensen, J. L. Peng, and R. L. Greene, "Single-crystal neutron-diffraction structures of reduced and oxygenated $\mathrm{Nd}_{2-x} \mathrm{Ce}_{x} \mathrm{CuO}_{y}$," Physical Review B: Condensed Matter and Materials Physics, vol. 53, no. 9, pp. 5157-5159, 1996.

[2] P. Richard, G. Riou, I. Hetel, S. Jandl, M. Poirier, and P. Fournier, "Role of oxygen nonstoichiometry and the reduction process on the local structure of $\mathrm{Nd}_{2-x} \mathrm{Ce}_{x} \mathrm{CuO}_{4 \pm \delta}$," Physical Review BCondensed Matter and Materials Physics, vol. 70, no. 6, Article ID 064513, 2004.

[3] P. K. Mang, S. Larochelle, A. Mehta et al., "Phase decomposition and chemical inhomogeneity in $\mathrm{Nd}_{2-x} \mathrm{Ce}_{x} \mathrm{CuO}_{4 \pm \delta}$," Physical Review B, vol. 70, no. 9, Article ID 094507, 2004.

[4] H. J. Kang, P. Dai, B. J. Campbell et al., "Microscopic annealing process and its impact on superconductivity in T'-structure electron-doped copper oxides," Nature Materials, vol. 6, no. 3, pp. 224-229, 2007.

[5] Y. Tokura, H. Takagi, and S. Uchida, "A superconducting copper oxide compound with electrons as the charge carriers," Nature, vol. 337, no. 6205, pp. 345-347, 1989.

[6] R. J. Cava, H. Takagi, R. M. Fleming et al., "Metal atom stoichiometry in the electron doped superconductor ( $\mathrm{Nd}$, Ce) ${ }_{2} \mathrm{CuO}_{4}$," Physica C: Superconductivity and its applications, vol. 199, no. 1-2, pp. 65-72, 1992.

[7] A. C. W. P. James, D. W. Murphy, and S. M. Zahurak, "Superconductivity at $27 \mathrm{~K}$ in fluorine-doped $\mathrm{Nd}_{2} \mathrm{CuO}_{4}$," Nature, vol. 338, no. 6212, pp. 240-241, 1989.

[8] H. Takagi, S. Uchida, and Y. Tokura, "Superconductivity produced by electron doping in $\mathrm{CuO}_{2}$-layered compounds," Physical Review Letters, vol. 62, no. 10, pp. 1197-1200, 1989.

[9] M. Plebańczyk, T. Klimczuk, and W. Sadowski, "Influence of the improved reduction technique on superconductivity in $\mathrm{Nd}_{1.85} \mathrm{Ce}_{0.15} \mathrm{Cu}_{1 \pm y} \mathrm{O}_{4-\delta}$, Physica C: Superconductivity and Its Applications, vol. 460-462, pp. 432-433, 2007.

[10] R. Horyń, "Crystallochemical characterization of Ce/RE substituted phases of $\mathrm{T}^{\prime}$-structure type: quantitative analysis of $\mathrm{Cu}$ valence $(V)$ and its content $(1-y)$ in superconducting sample of nominal composition $\mathrm{Nd}_{1.95-x} \mathrm{Ce}_{x} \mathrm{CuO}_{4}(x=0.15)$," Journal of Alloys and Compounds, vol. 524, pp. 77-82, 2012.

[11] J. G. Bednorz and K. A. Müller, "Possible high $T_{c}$ superconductivity in the Ba-La-Cu-O system," Zeitschrift für Physik B Condensed Matter, vol. 64, no. 2, pp. 189-193, 1986.

[12] J. Zhou, S. Sinha, and J. B. Goodenough, "Comment on, 'identification of a superoxide in superconducting $\mathrm{La}_{2} \mathrm{CuO}_{4+\delta}$ by X-ray photoelectron' spectroscopy," Physical Review B, vol. 39, no. 16, pp. 12331-12333, 1989.

[13] E. Takayama-Muromachi, T. Sasaki, and Y. Matsui, "Direct oxidation of $\mathrm{La}_{2} \mathrm{CuO}_{4}$ in an aqueous solution of $\mathrm{KMnO}_{4}$," Physica C: Superconductivity and its Applications, vol. 207, no. 1-2, pp. 97-101, 1993.

[14] Y. C. Lan, X. L. Chen, Y. G. Cao et al., "Structure and superconducting properties of chemically oxidized $\mathrm{La}_{2} \mathrm{CuO}_{4+y}$ under hydrothermal conditions," Physica C: Superconductivity and Its Applications, vol. 336, no. 1-2, pp. 151-156, 2000.
[15] Q. Tu, X. Chen, B. Ma, Z. Zhao, Y. Lan, and J. Liang, "Super-

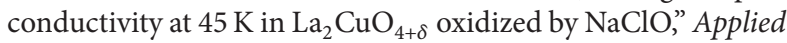
Physics A: Materials Science \& Processing, vol. 74, no. 1, pp. 7982, 2002.

[16] Y. C. Lan, X. L. Chen, G. C. Che, Y. G. Cao, J. Y. Li, and Q. Y. Tu, "Hydrothermal oxidation: a new chemical oxidation method to dope oxygen in $\mathrm{La}_{2} \mathrm{CuO}_{4+\delta}$," Superconductor Science and Technology, vol. 13, no. 10, pp. 1415-1418, 2000.

[17] Y. C. Lan, X. L. Chen, Y. G. Cao et al., "Low-temperature synthesis and photoluminescence of AlN," Journal of Crystal Growth, vol. 207, no. 3, pp. 247-250, 1999.

[18] Y. C. Lan, X. L. Chen, Y. P. Xu, Y. G. Cao, and F. Huang, "Syntheses and structure of nanocrystalline gallium nitride obtained from ammonothermal method using lithium metal as mineralizator," Materials Research Bulletin, vol. 35, no. 14-15, pp. 2325-2330, 2000.

[19] Y. C. Lan, X. L. Chen, M. A. Crimp et al., "Single crystal growth of gallium nitride in supercritical ammonia," Physica Status Solidi (c), vol. 2, no. 7, pp. 2066-2069, 2005.

[20] A. Boultif and D. Loueer, "Indexing of powder diffraction patterns for low-symmetry lattices by the successive dichotomy method," Journal of Applied Crystallography, vol. 24, no. 6, pp. 987-993, 1991.

[21] R. A. Young, A. Sakthivel, T. S. Moss, and C. O. PaivaSantos, "DBWS-9411: an upgrade of the DBWS*.* programs for Rietveld refinement with PC and main-frame computer," Journal of Applied Crystallography, vol. 28, part 3, pp. 366-367, 1995.

[22] D. C. Harris and T. A. Hewston, "Determination of $\mathrm{Cu}^{3+} / \mathrm{Cu}^{2+}$ ratio in the superconductor $\mathrm{YBa}_{2} \mathrm{Cu}_{3} \mathrm{O}_{8-x}$, Journal of Solid State Chemistry, vol. 69, no. 1, pp. 182-185, 1987.

[23] M. Matsuda, K. Yamada, K. Kakurai et al., "Three-dimensional magnetic structures and rare-earth magnetic ordering in $\mathrm{Nd}_{2} \mathrm{CuO}_{4}$ and $\mathrm{Pr}_{2} \mathrm{CuO}_{4}$," Physical Review B, vol. 42, no. 16, pp. 10098-10107, 1990.

[24] D. Nicholis, Inorganic Chemistry in Liquid Ammonia, Elsevier Scientific, Amsterdam, The Netherlands, 1979.

[25] H. Wilhelm, C. Cros, E. Reny, G. Demazeau, and M. Hanfland, "Influence of pressure on the crystal structure of $\mathrm{Nd}_{2} \mathrm{CuO}_{4}$ ", Journal of Materials Chemistry, vol. 8, no. 12, pp. 2729-2732, 1998.

[26] F. Izumi, Y. Matsui, H. Takagi, S. Uchida, Y. Tokura, and H. Asano, "Neutron and electron diffraction study of the electron-doped superconductor $\mathrm{Nd}_{1.845} \mathrm{Ce}_{0.155} \mathrm{CuO}_{4-y}$," Physica C: Superconductivity and its Applications, vol. 158, no. 3, pp. 433439, 1989. 

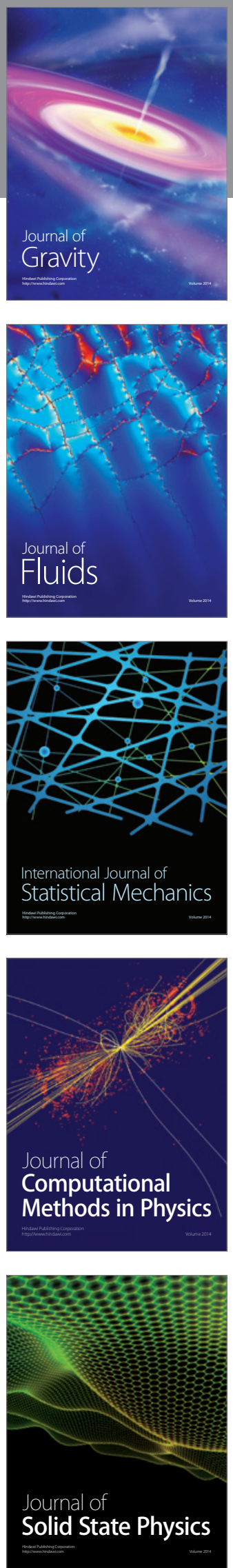

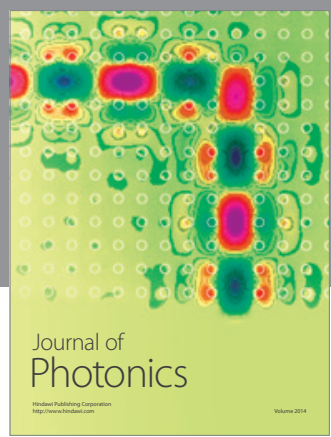

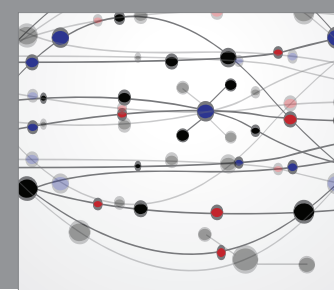

The Scientific World Journal

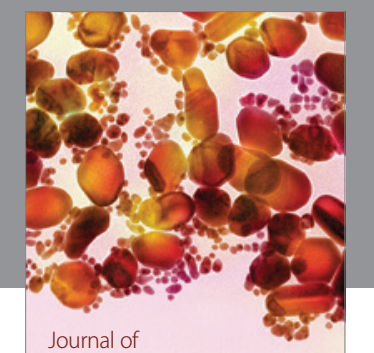

Soft Matter
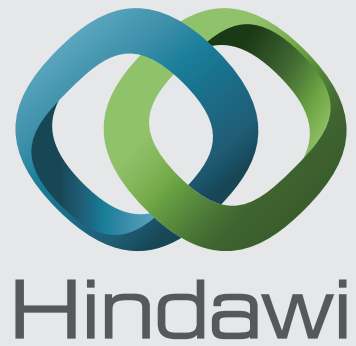

Submit your manuscripts at

http://www.hindawi.com
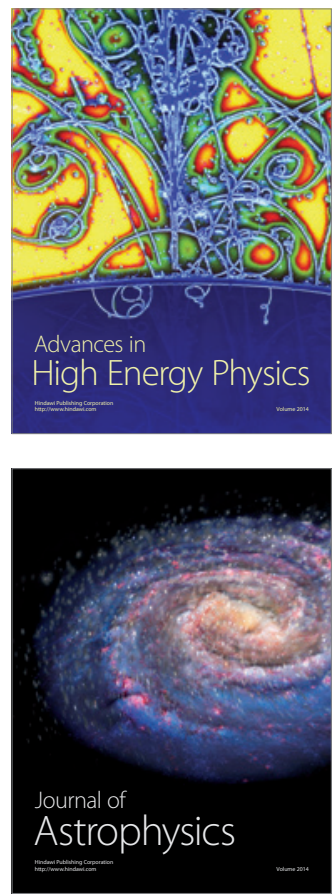
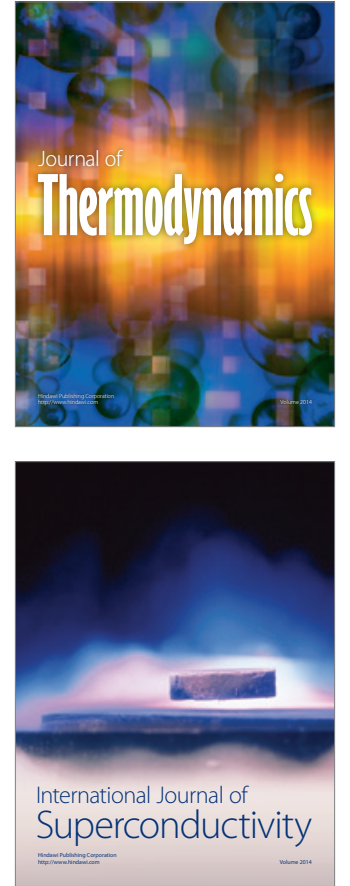
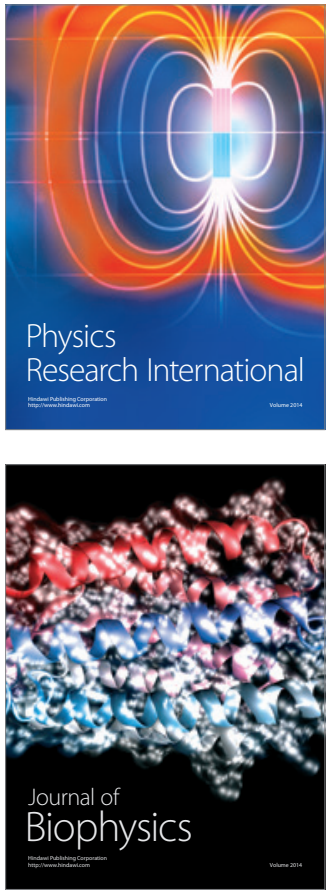
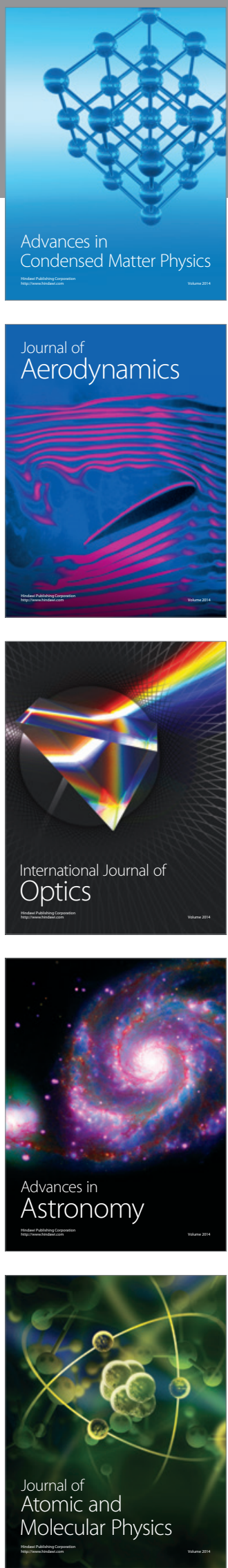